\title{
Psoriasis in Children and Adolescents: Diagnosis, Management and Comorbidities
}

\author{
I. M. G. J. Bronckers ${ }^{1}$ - A. S. Paller ${ }^{2}$ M. J. van Geel ${ }^{1}$. \\ P. C. M. van de Kerkhof $^{1}$ - M. M. B. Seyger ${ }^{1}$
}

Published online: 14 June 2015

(c) The Author(s) 2015. This article is published with open access at Springerlink.com

\begin{abstract}
Psoriasis is a common chronic immune-mediated inflammatory skin disorder and begins in childhood in almost one-third of the cases. Although children present with the same clinical subtypes of psoriasis seen in adults, lesions may differ in distribution and morphology, and their clinical symptoms at presentation may vary from those reported by adult patients. Nevertheless, diagnosis of psoriasis is primarily based on clinical features. Pediatric psoriasis can have a profound long-term impact on the psychological health of affected children. Additionally, pediatric psoriasis has been associated with certain comorbidities, such as obesity, hypertension, hyperlipidemia, diabetes mellitus and rheumatoid arthritis, making early diagnosis and management essential. As guidelines are lacking and most (systemic) treatments are not approved for use in children, treatment of pediatric psoriasis remains a challenge. A prospective, multicenter, international registry is needed to evaluate these treatments in a standardized manner and ultimately to develop international guidelines on pediatric psoriasis. This article reviews current concepts in pediatric psoriasis including epidemiology, clinical features, diagnosis, the role of topical and systemic agents and the association with other morbidities in childhood.
\end{abstract}

I. M. G. J. Bronckers

inge.bronckers@radboudumc.nl

1 Department of Dermatology, Radboud University Medical Center, René Descartesdreef 1, PO Box 9101, 6500 HB Nijmegen, The Netherlands

2 Department of Dermatology and Pediatrics, Northwestern University Feinberg School of Medicine, Chicago, IL, USA

\section{Key Points}

In pediatric psoriasis patients, lesions may differ in distribution and morphology, and their clinical symptoms at presentation may vary from those reported by adults.

There are currently no international standardized guidelines for medical treatment of pediatric psoriasis. Treatment is primarily based on published case series, guidelines for adult psoriasis, expert opinions and experience with these drugs in other pediatric disorders.

Pediatric psoriasis has a high impact on the quality of life of those affected.

There is increasing evidence suggesting an association of pediatric psoriasis with certain other morbidities, including hyperlipidemia, obesity, hypertension, diabetes mellitus and rheumatoid arthritis.

\section{Introduction}

Psoriasis is a common chronic immune-mediated inflammatory disorder affecting the skin, nails and joints in both children and adults. The skin disorder is estimated to affect $2.0-3.5 \%$ of the global population $[1,2]$. A recent publication by Parisi et al. reported even higher percentages, with ranges up to $8.5 \%$ depending on the studied population [3]. Psoriasis begins in childhood in almost one-third of the cases $[1,4,5]$, and the published incidence rates in 
children have more than doubled since 1970 [6]. Psoriatic skin lesions are characterized by well defined erythematous scaly plaques, and tend to have a chronic relapsing and remitting course. Severity ranges from a few scattered plaques to involvement of almost the entire body surface. Psoriasis in children and adolescents can have a significant impact on quality of life by interfering with self-esteem, family and social relationships and school and work [7-9]. Children suffering from psoriasis also have a higher prevalence of comorbidities, including obesity, diabetes mellitus, hypertension, rheumatoid arthritis, Crohn's disease and psychiatric disorders, compared with children without psoriasis [1, 10-12]. Because of the burden of disease and the associated comorbidities, early diagnosis and management in children are essential.

\section{Epidemiology}

Prevalence rates vary slightly, depending on age, gender, geographical location, definition of prevalence, study design and case definition. Clinical presentation and psoriasis severity may also contribute to variation in prevalence and incidence numbers [3]. Although pediatric psoriasis is not uncommon, limited epidemiology data are available to date. It is estimated that approximately $30-50 \%$ of adults with psoriasis developed psoriasis before 20 years of age [5, 13, 14]. Gelfand et al. found that the prevalence of psoriasis in childhood in the UK was about $0.55 \%$ in children aged 0-9 years and $1.37 \%$ in children aged 10-19 years [4]. This study also demonstrated that the prevalence increased more rapidly in females compared with males younger than 20 years. This finding is probably not due to females paying closer attention to their skin, but suggests an interaction between sex and the development of the psoriasis phenotype in young patients [4]. Comparable prevalence results have been reported within the German (age 0-9, $0.18 \%$; age $10-19,0.83 \%$ ) [1] and Dutch populations (age 0-10, $0.4 \%$; age 11-19, $1.0 \%$ ) [13]. In contrast to Europe, pediatric psoriasis was almost absent in an epidemiological study on childhood dermatoses performed in Asia [15, 16]. This worldwide geographical variation seems to reflect the fact that psoriasis is a complex disease triggered by environmental factors in genetically susceptible subjects [17].

The incidence of pediatric psoriasis has more than doubled between 1970 and 2000. A study by Tollefson et al. found the overall annual age- and sex-adjusted incidence of psoriasis to be 40.8 [95\% confidence interval (CI) 36.6-45.1] per 100,000 . An increase in triggering factors for psoriasis such as psychosocial stress, infections and being obese or overweight could be potential explanations for this development [6]. Other exacerbating factors include trauma or irritation of the skin and the use of certain medications such as lithium, $\beta$-adrenergic antagonists and tumor necrosis factor alpha (TNF- $\alpha$ ) inhibitors in children with Crohn's disease or juvenile idiopathic arthritis (JIA) [18-20]. Most studies report no gender bias in pediatric psoriasis. Tollefson et al. described a female to male gender ratio of 1.10 [6]. These findings were similar to other epidemiological studies from Australia, the USA, India and China [5, 21-24]. However, a recent multicenter, cross-sectional study performed in 181 children with plaque psoriasis in the USA reported a female to male gender ratio of 1.48 [25]. This female predominance was also demonstrated by others [26, 27]. The mean age of onset varied from 8 to 11 years [6, 28-30]. Interestingly, Augustin et al. demonstrated an almost linear increase in prevalence rates between 0 and 18 years rather than a "peak of onset" [1].

About $30 \%$ of individuals with psoriasis (children and adults) have an affected first-degree family member [17].

The prevalence of psoriasis patients with an affected family member is observed to be greater in early-onset psoriasis (defined as psoriasis onset before the age of 16) than in adult-onset psoriasis (defined as psoriasis onset after the age of 16) [5, 29, 31, 32]. Chiam et al. compared a Dutch and Singaporean group of children with psoriasis and reported that more Dutch children than Singaporean children had a first- or second-degree family member with psoriasis (73.3 vs. $13.6 \%$ ) [26]. In an Australian population, $71 \%$ of children with psoriasis had a first-degree relative with psoriasis. A positive family history of psoriasis was reported in $51.4 \%$ of pediatric psoriasis patients in a multicenter, cross-sectional trial in the USA, with affected members being first-degree relatives in $59.8 \%$ of those cases [25]. These differences point to the role of genetic background within each population of patients with juvenile psoriasis [23, 28].

\section{Clinical Features}

Although children present with the same clinical subtypes of psoriasis seen in adults, lesions may differ in distribution and morphology, and their clinical symptoms at presentation may vary from those reported by adults. In childhood, typical erythematous plaques with overlying white scale are often thinner and smaller and psoriasis lesions tend to develop more often on the face and flexural areas. These lesions are characterized by maceration and less prominent scale [22, 28]. Despite these predilection sites, psoriasis papules and plaques can develop on any skin area and are usually symmetrically distributed [33]. Young children usually present with a diaper rash that is unresponsive to irritant diaper dermatitis treatment. Psoriatic diaper rash is 
seen in young infants and is characterized by sharply demarcated, minimally elevated erythematous plaques in the diaper area, involving the inguinal folds. The lesions are often macerated, and can develop into a widespread eruption within 1-2 weeks [32]. Morris et al. reported that $26 \%$ of patients had a history of psoriasis diaper rash, but the diagnosis of true psoriasis in these infants remains controversial. Diaper psoriasis can be particularly difficult to treat [23]. In older children, up to $75 \%$ manifests with chronic plaque psoriasis [26, 34]. This is the most common type of psoriasis in children and adults and is characterized by well defined erythematosquamous papules or plaques with overlying silvery-white scale. The lesions vary in size and develop primarily on the scalp, face and extensor surfaces of the elbow and knee. The scalp is the most frequently involved area and often the first site of presentation in children [29, 35].

Guttate psoriasis is the second most common type of psoriasis in children [21, 29]. Griffiths and Barker defined guttate psoriasis as an acute form of psoriasis in which papules erupt on the trunk approximately 2 weeks after a $\beta$-hemolytic streptococcal or viral infection [17]. According to this definition, guttate psoriasis is self-limiting, resolving within 3-4 months of onset [17]. It has been reported that a proportion of individuals with guttate psoriasis eventually develop plaque psoriasis $[22,24,25,36$, 37]. Mercy et al. suggested that the risk of severe disease is higher if psoriasis started as guttate psoriasis which persisted [25]. Prospective cohort studies are needed to further determine features and percentages of children with guttate psoriasis who develop plaque psoriasis.

Pustular psoriasis is seen in only $1.0-5.4 \%$ of children with psoriasis. In a minority of these patients, mutations of the interleukin-36 (IL-36) receptor antagonist (IL36RN) gene and subsequent upregulation of IL-1 production have been identified [38]. Pustular psoriasis is characterized by localized or generalized superficial sterile pustules and can be accompanied by fever, malaise and arthralgias in the case of classical von Zumbusch type. Although pustular psoriasis is more common in adults, von Zumbusch pustular psoriasis and pustular psoriasis with an annular configuration occur more frequently in childhood [31, 39].

Other less common subtypes of psoriasis are inverse psoriasis, palmoplantar psoriasis, isolated facial psoriasis, linear psoriasis and erythrodermic psoriasis [17]. Erythrodermic psoriasis is characterized by erythema and scaling on more than $90 \%$ of the body surface area. The condition is extremely rare in children and can be life-threatening because of severe hypothermia, hypoalbuminemia and cardiac failure [17, 32].

Psoriasis of the skin can be accompanied by changes of the nail plate and nail bed. Nail changes have been reported in up to $40 \%$ of children with psoriasis and more often in boys than in girls $[25,26,33]$. Nail changes can precede, coincide with, or develop after skin psoriasis. Whether these changes relate to patient age or disease severity vary among studies $[25,40]$. The most common presentation is pitting of the nail plate. Other characteristics include oil spots, onycholysis (distal separation of the nail plate from the nail bed), subungual hyperkeratosis, onychodystrophy and splinter hemorrhages [41]. Juvenile psoriatic arthritis (JPsA) is another manifestation of psoriasis in children. Because of difficulties in diagnosis and classification of psoriatic arthritis in children, prevalence data range from 1 to $10 \%$ of children with psoriasis $[22,25]$. Approximately $7 \%$ (range $0-11 \%$ ) of all patients with JIA appear to have JPsA [42-46]. JPsA is included under the term JIA. Following the introduction of the International League of Associations for Rheumatology (ILAR) criteria for JIA, JPsA has become a better recognized inflammatory arthritis in children. According to these criteria, JPsA can be diagnosed in the presence of skin psoriasis, or in the absence of a rash, if there are nail changes and/or a firstdegree relative with psoriasis [47]. Psoriatic arthritis is more common in adults, with prevalence data up to $30 \%$ [34, 48, 49]. The peak of onset in childhood is between ages 9 and 12, and the skin psoriasis often precedes psoriatic arthritis. Although a relationship between nail involvement and psoriatic arthritis in adults has been suggested, recent studies in both children and adults do not support this correlation $[25,32,50]$.

\section{Diagnosis}

In addition to the clinical features described above, children often present with a thinner surface scale compared with adults. When scraping off scales, punctuate bleeding spots occur, a phenomenon known as the Auspitz sign. The occurrence of lesions in areas of trauma, also called isomorphic response or Koebner phenomenon, and residual pigmentation following healing of lesions are other typical diagnostic features of psoriasis [34].

Although the diagnosis of psoriasis is primarily based on clinical features, biopsy can help to confirm the diagnosis in children with atypical presentations. Histological features of psoriasis include parakeratosis, loss of the granular cell layer, elongation of the rete ridges, neutrophilic aggregates within the epidermis (microabscesses of Munro), dilated blood vessels in the dermis, and perivascular lymphocytic infiltrates [17, 51, 52]. These characteristics may vary depending on site of biopsy, psoriasis subtype, and whether children have been treated with topical and/or systemic treatments. Given that the diagnosis is usually made on the basis of morphology and distribution, a biopsy is virtually never performed, especially not in 
children. In atypical cases in which a diagnosis is required, topical therapy should ideally be discontinued prior to biopsy to avoid alteration of histological features [53].

Dermoscopy has become a standard diagnostic tool in dermatology. Although this technique permits visualization of morphological structures invisible to the naked eye, it is not commonly used in the diagnosis of psoriasis. Lallas et al., however, suggested that dermoscopy could distinguish psoriasis from other common skin diseases such as dermatitis [55]. Dotted vessels regularly distributed over a light red background and diffuse superficial white scales are typical dermatoscopic characteristics of a psoriasis plaque $[54,55]$. Further research is warranted to determine the added value of dermoscopy in diagnosis and predicting response to treatment.

\section{Management}

Treating pediatric psoriasis can be challenging and requires careful compliance to a specific treatment regimen. Poor treatment adherence is rampant in psoriasis, in particular to topical agents $[56,57]$. Educating the patient and family on the chronicity of psoriasis, triggering factors, and treatment modalities is important, in addition to prescribing treatment. Timing of the first return visit may be a practical tool to enhance patient adherence [29]. Return visits can induce "white coat compliance" in which the expectation of frequent monitoring can enhance patients' use of medication [58]. Psychosocial support is another important component of therapy for children with psoriasis [7].

There are currently no international standardized guidelines for medical treatment of pediatric psoriasis. To date, treatment is primarily based on published case reports, guidelines for adult psoriasis, expert opinions and experience with these drugs in other pediatric disorders. The range of psoriasis treatments has been expanded during the past several years, and multiple topical agents, phototherapy and systemic and biological agents are available to date [53]. Several factors need to be taken into account when selecting a specific treatment, e.g., age, quality of life, severity of psoriasis, location of psoriasis, type of psoriasis, tolerability, safety and patient preferences [59-61].

\section{Topical Treatments}

The majority of children with psoriasis can be managed with topical treatment, which is considered first-line therapy in psoriasis. However, most are not approved for pediatric use, requiring off-label prescribing [61]. The most commonly used topical agents will be reviewed below. The vehicle for treatment is important and depends on the location of psoriasis, lesional characteristics, and patient preference [62]. Available vehicles include creams, ointments, foams, gels and lotions.

\subsection{Topical Corticosteroids}

Topical steroids are the most commonly prescribed medications to treat psoriasis in all age groups. Steroids are available in a wide variety of strengths and vehicles. In adults, low- to mid-potency corticosteroids are used in facial, flexural and genital lesions, with use of high-potency corticosteroids in combination with penetration enhancers in areas of thick skin, such as the palms and the soles. In a systematic review on treatments in childhood psoriasis, three studies on the efficacy and safety of topical corticosteroids were reported [63]. The total number of treated children in these three studies was 20 , with a treatment period of 2 weeks. Based on these studies, it was concluded that halobetasol cream $0.05 \%$ and clobetasol propionate emulsion $0.05 \%$ are efficacious in pediatric plaque psoriasis. Reported side effects were relatively mild in the treatment period of 2 weeks, with burning sensation at the site of application or skin atrophy reported most frequently [63-65]. Apart from these studies with the strongest steroids available, no reports on the efficacy and safety of topical corticosteroids in pediatric psoriasis were found. Potential side effects of (prolonged) use in adults are skin atrophy/striae, telangiectasias, acneiform dermatitis, tachyphylaxis, periorificial dermatitis, hypertrichosis and, less commonly, suppression of the hypothalamic-pituitary-adrenal axis. Therefore, corticosteroids should be used with caution through intermittent or rotational use to limit possible side effects [29, 32].

\subsection{Vitamin D Analogs Alone and in Combination with Topical Corticosteroids}

Studies with topically administered calcipotriol and calcitriol have shown efficacy in pediatric psoriasis patients with only mild side effects [63]. Localized skin irritation and pruritus are the most common side effects, and use of these preparations is therefore avoided on areas with thinner skin, such as the face, genital and flexural areas [53]. However, calcitriol ointment has been found to be less irritating than calcipotriol ointment if used in intertriginous psoriasis [29, 62]. Systemic absorption of vitamin D and increasing calcium levels could theoretically occur, but are unlikely if used appropriately [34]. Use of up to $45 \mathrm{~g} / \mathrm{m}^{2} /$ week in pediatric patients with psoriasis does not seem to influence calcium levels in children from 3 to 14 years $[66,67]$. Vitamin D analogs are not recommended in children under the age of 2 years [62]. 
Although vitamin D analogs may be used as monotherapy, they are often prescribed in combination with topical corticosteroids, leading to drug synergy and a steroid-sparing effect $[32,68]$. In order to avoid separate applications and to enhance patient compliance, a commercially available compounded formulation containing calcipotriol and betamethasone dipropionate has been developed. Three studies describe the efficacy and safety of this formulation in pediatric psoriasis [69-71]. In a prospective study with a clinical practice cohort, 73 children (aged 3-18 years) with plaque type psoriasis were treated with calcipotriol/betamethasone dipropionate ointment once daily for 4 weeks and 4 days a week thereafter, with a median treatment duration of 35 weeks. The greatest effect of calcipotriol/betamethasone ointment was achieved within the first weeks. Continued treatment seemed to stabilize psoriasis in these children. Five children reported an adverse event, most commonly the development of striae [69]. A multicenter, open-label study by Gooderham et al. found calcipotriol/betamethasone dipropionate gel applied once daily for 8 weeks in adolescents (aged 12-17 years) with moderate to very severe plaque psoriasis to be well tolerated and effective. [70]. Oostveen et al. demonstrated the effectiveness of calcipotriene/betamethasone dipropionate gel in pediatric scalp psoriasis (patient ages 4-17 years) within the first 12 weeks of treatment (84 treatment episodes), with maintenance of this effect through the 48 weeks of follow-up. Striae of the skin (arms, trunk and legs) were described in three patients [71].

\subsection{Calcineurin Inhibitors}

In adults, tacrolimus (0.03 and $0.1 \%)$ and pimecrolimus (1\%) have proven to be effective on psoriasis lesions on the face, genitalia and flexures and are a good alternative for psoriasis in these areas sensitive to the adverse effects of long-term topical steroid use [72]. The efficacy and safety of tacrolimus $0.1 \%$ applied twice daily in pediatric patients with psoriasis was evaluated in two nonrandomized clinical trials. All patients had cleared or improved substantially with the use of tacrolimus ointment within the first 30 days of treatment. The only reported adverse effect was pruritus in one patient $[73,74]$. There is currently not enough evidence for the use of pimecrolimus $1 \%$ cream in the pediatric psoriasis population, as this was only described in two patients [63]. Concomitant treatment with phototherapy and excessive sun exposure should be avoided because of the possible increased risk for skin cancer and lymphoma. However, further research is warranted to study possible long-term adverse effects [60].

\subsection{Dithranol}

Dithranol, also referred to as anthralin, is a topical agent with both anti-inflammatory and anti-proliferative properties and no significant systemic absorption. It is an effective and safe treatment option for pediatric psoriasis [32, 36]. Short-contact dithranol at higher concentrations (0.1-3\%) and applied for shorter periods of time (10-30 min daily until irritation develops) maintains treatment efficacy but diminishes the risk of irritation and staining. Short-contact dithranol involves an intense treatment schedule and is preferably administered in a day care setting. In a retrospective study determining the position of dithranol in the treatment of pediatric psoriasis, a good or excellent result was achieved in $73.2 \%$ of the patients. A median treatment period of 2 months was needed to achieve a median duration of remission of 5.5 months [75]. Recently, Oostveen et al. demonstrated the efficacy and safety of short-contact dithranol therapy in a prospective observational study in 34 pediatric patients [76]. A significant reduction in Psoriasis Area and Severity Index (PASI) score of $69.3 \%$ was found, and the only reported adverse event was irritation of the skin. The efficacy and safety of short-contact dithranol treatment in day care with telemedicine (one visit per week and one scheduled video call via Skype) compares well to administration in a regular day care setting (two visits per week) [76]. Although effective and safe to use in pediatric patients, dithranol can stain clothes and cause local skin irritation, particularly in facial, flexural, erythrodermic or pustular psoriasis [34, 36].

\subsection{Phototherapy}

Several studies have reported the use of phototherapy in pediatric psoriasis. Narrow band ultraviolet B light (nbUVB) seems to be an effective and well tolerated alternative treatment in pediatric patients with plaque and guttate psoriasis [63, 77] that is poorly controlled with topical therapy. However, logistics and frequency of appointments could be an issue for some patients and their parents. In 2011, a retrospective study in pediatric psoriasis patients (range 2-18 years) demonstrated complete clearance in $51 \%$ and a good response (at least $75 \%$ improvement) in $41 \%$ of the children. Mean duration of treatment was 3.3 months [78]. Only a small number of pediatric patients were treated with psoralen plus UVA radiation (PUVA), which is now rarely used in children because of long-term toxicity [53, 79]. Short-term side effects of phototherapy include erythema, burning, pruritus and blistering. Anxiety can also be a significant problem in children [80]. Although long-term side effects (e.g., carcinogenesis, photoaging) of nbUVB and PUVA have been 
seen in adults [81], current evidence is heterogeneous and needs to be interpreted with caution $[82,83]$. There is a need for long-term follow-up in order to further clarify these associations, especially in the pediatric population $[63,79]$.

\section{Systemic Treatments and Biologics}

In children with moderate to severe psoriasis recalcitrant to topical treatment, systemic treatments are indicated [63]. However, the choice of agent remains a challenge because of the limited number of clinical trials and lack of guidelines in this age group [84]. Most of the systemic treatments are not approved to use in children and are used offlabel. Therefore, daily practice clinical decision making can be complicated and challenging. A systematic review on the efficacy and safety of all systemic treatments in pediatric psoriasis by van Geel et al. provided evidencebased recommendations for the use of these agents in the pediatric psoriasis population [85].

\subsection{Methotrexate}

Methotrexate (MTX) has been approved for treatment of severe psoriasis in adults. However, in children, MTX is only approved for treatment of JIA, inflammatory bowel disease (IBD) and certain malignancies [29, 86]. The use of MTX in pediatric psoriasis has also been studied [85]. A recent analysis of a prospective registry demonstrated the safety and efficacy of oral and/or subcutaneous MTX in 25 children with plaque psoriasis [87]. Based on the available evidence, MTX is considered to be the systemic treatment of choice in children with moderate to severe plaque psoriasis and its variants $[85,87,88]$. MTX can be administrated either orally or subcutaneously [89]. To date there is no consensus about MTX dosing regimen and treatment duration in pediatric psoriasis. As soon as therapeutic control is achieved, it is recommended to taper the dose to an effective but lower maintenance dose in order to reduce side effects [86]. Folic acid is routinely administered to further reduce these side effects. However, optimal dose and timing of folic acid administration is still unclear [84, 90, 91].

The most common side effects include nausea, vomiting, fatigue, stomatitis and abnormal liver function tests. Bone marrow suppression, pulmonary toxicity, infections and hepatotoxicity including liver fibrosis have been rarely reported in children [60, 86, 87, 92]. Bone marrow suppression is potentially life-threatening, and generally occurs within the first months of treatment. Laboratory testing is done on a regular basis to monitor for these potential side effects. In addition, concomitant use of medications such as nonsteroidal anti-inflammatory drugs and trimethoprim/sulfamethoxazole needs to be avoided as these can interact with MTX and increase its potential toxicity [29, 86]. Alcohol is also strongly discouraged during MTX use because of its hepatotoxicity [92].

\subsection{Cyclosporine}

Cyclosporine is an immunosuppressant drug approved for treatment of psoriasis in adults. It has a rapid onset of action (2-4 weeks) and is therefore considered to be an ideal drug for controlling unstable disease in this population [89, 93-95].

To date, the efficacy of cyclosporine in pediatric psoriasis remains unclear [85]. Children may require higher doses than recommended in adults, because of differences in pharmacokinetics and the greater body surface area to weight ratio in children $[89,94,96]$. Reported side effects include nephrotoxicity, hypertension, nausea and diarrhea. Because evidence in children is limited, the lowest possible dose and shortest treatment period should be used. Close monitoring of blood pressure and renal function is required $[86,90]$. The long-term risk of non-melanoma skin cancers has also been described. Concomitant phototherapy should be avoided to further reduce the risk of these malignancies $[29,60]$.

\subsection{Retinoids}

The efficacy and safety of retinoid treatment in pediatric psoriasis treatment has been shown primarily in pustular and erythrodermic psoriasis [85]. Etretinate was previously used but is no longer commercially available, and it has been replaced by acitretin, its active metabolite. The use of acitretin has only been described in a few children with psoriasis [97, 98]. Mucocutaneous side effects such as cheilitis, xerosis, epistaxis, skin fragility, hair loss and ocular toxicities have frequently been reported [60, 85]. Laboratory follow-up is needed to monitor for elevated liver enzymes and triglycerides. In addition, prolonged retinoid use has been associated with diffuse idiopathic skeletal hyperostosis, premature epiphyseal closure (at high doses) and decreased bone mineral density [29, 99]. Due to the teratogenicity of oral retinoids and concerns about delayed clearance, the use in adolescent girls should be considered carefully. Pregnancy must be avoided until at least 3 years after stopping therapy $[34,36]$.

\subsection{Fumaric Acid Esters}

Fumaric acid esters (FAE) have a broad range of immunomodulatory effects and are registered for the treatment of moderate-to-severe plaque psoriasis in adults 
in Germany [90]. In adults, doses can be titrated to a maximum of $720 \mathrm{mg}$ daily, depending on clinical response and tolerability [84, 90, 100, 101]. Although data on pediatric use are limited, a retrospective case series of 14 children demonstrated complete clearance of psoriasis in $36 \%$, good improvement in $7 \%$, partial response in $21 \%$ and non-response in $36 \%$ of pediatric patients. The median duration of treatment was 10 months (range 1-80 months). A starting dose of dimethylfumarate of $30 \mathrm{mg}$ was given, and was increased to a maximum daily dosage of $720 \mathrm{mg}$ on the basis of clinical response and tolerability [100]. Reported side effects include flushing, gastrointestinal complaints, eosinophilia, transient shifts in leukocyte counts, and elevated hepatic transaminases. Mild proteinuria and increased serum creatinine levels may also occur [100, 102-104]. Although evidence to date is limited, FAE can also be considered in pediatric psoriasis if MTX is ineffective or contraindicated [85].

\subsection{Biologics}

Biologics are relatively new pharmacological agents that target specific mediators of the inflammatory cascade in psoriasis, including TNF- $\alpha$ and IL-12/23. Biologics offer more favorable dosing regimens and require less frequent lab monitoring than conventional systemic therapies. International guidelines about the use of biologics in pediatric psoriasis are lacking [89]. Moreover, biologics have been associated with complications in both children and adults, including opportunistic infections, reactivation of latent tuberculosis and malignancies, in particular lymphomas. Although these complications are rare, and primarily reported in patients with arthritis, IBD or sarcoidosis, the advantages must be balanced with some caution [89, 106]. As long-term safety data are lacking, potential risks should be discussed with the patient and parents prior to decision making.

\subsubsection{Etanercept}

Although approved in Europe and Canada for children aged 8 years and older, the US Food and Drug Administration (FDA) has yet to approve psoriasis as an indication for etanercept in the pediatric population [86, 89, 107]. In 2008, a double-blind, multicenter, phase III, randomized controlled trial evaluated the safety and efficacy of etanercept in children aged 4-17 with moderate-to-severe plaque psoriasis. Etanercept was well tolerated and demonstrated a significantly reduced severity of disease at week 48 and 96. Most common short-term side effects included infections such as pharyngitis, bronchitis and gastroenteritis. No deaths, cancers, opportunistic infections, tuberculosis or demyelination events were reported [105, 108]. Although long-term etanercept treatment seems well tolerated in children with JIA, the association between TNF blockers and development of malignancy remains unclear [109, 110]. Therefore, etanercept is still considered to be a third-line drug in severe and/or recalcitrant psoriasis in children [85, 89]. A clinical trial evaluating the long-term safety and efficacy of etanercept for treatment of pediatric psoriasis is ongoing [111].

\subsection{Other Biologics and Future Prospects}

Other biologics that could play a role in pediatric psoriasis in the near future are adalimumab, infliximab and ustekinumab. In 2008, the FDA approved adalimumab for the treatment of JIA in children aged 4 years and older. Currently, this biologic is also used off-label for pediatric psoriasis, IBD and uveitis [60, 106]. Only two case reports describe the use of adalimumab in pediatric psoriasis [85]. In these patients, adalimumab was prescribed after failure of other systemic agents and demonstrated a favorable outcome [112, 113]. A multicenter, randomized, doubleblind study evaluating the efficacy of adalimumab versus methotrexate in pediatric patients aged 4-17 years with chronic plaque psoriasis has been completed [114], although results are not currently available. Adalimumab was recently granted marketing authorization in the EU for severe chronic plaque psoriasis in children aged 4 years and older who have had an inadequate response to or are inappropriate candidates for topical treatment and phototherapies.

Infliximab, which is the only TNF inhibitor administered by infusion, is FDA approved for the treatment of Crohn's disease in children aged 6 years and older [106]. In pediatric psoriasis, only four anecdotal case reports are available [85, 89, 111]. Ustekinumab was recently FDA approved for the treatment of adult psoriasis [89]. There are currently three case reports describing the use of ustekinumab in pediatric patients with psoriasis. All had an excellent response to ustekinumab, with two achieving total clearance at week 8 [115-117]. Future research is needed to determine efficacy and safety profiles and the role of these agents in the treatment of pediatric psoriasis. A phase III, multicenter, randomized, double-blind, placebo-controlled trial on the efficacy and safety of ustekinumab in the treatment of adolescents with plaque psoriasis (CADMUS trial) was recently completed. Respectively, 78.4 and $80.6 \%$ of adolescents (aged 12-18) receiving half-standard dosage $(0.375 \mathrm{mg} / \mathrm{kg})$ and standard dosage $(0.750 \mathrm{mg} / \mathrm{kg})$ achieved PASI75 at 12 weeks as compared with $10.8 \%$ of participants receiving placebo [111, 118]. 


\section{Comorbidities in Pediatric Psoriasis}

As in adult psoriasis, recent studies suggest the association of pediatric psoriasis with certain comorbidities. In an analysis of German health insurance data, a twofold increased risk of hyperlipidemia, obesity, hypertension, diabetes mellitus and rheumatoid arthritis was found in psoriasis patients under 18 years of age, as compared with healthy controls. Crohn's disease is noted four times more often as compared with unaffected controls [1]. Similar results have been found in a smaller insurance company database [119].

Obesity as a comorbidity of psoriasis has been the focus of much investigation. Koebnick et al. demonstrated that children who were overweight, moderately obese and extremely obese had 1.31-, 1.39- and 1.78-fold greater odds, respectively, of having psoriasis than children with normal weight [120]. Further, Paller et al. demonstrated the increased risk of being overweight or obese in pediatric psoriasis in a large international cross-sectional study in 5to 17 -year-old children with psoriasis [10]. The odds ratios (ORs) for obesity [body mass index (BMI) percentile $\geq 95$ th] and excess adiposity (BMI percentile $>85$ th) in psoriatic children were 4.29 and 2.65 , respectively. More children with severe psoriasis [OR $4.92 \quad(95 \%$ CI 2.20-10.99)] than with moderate psoriasis [OR 3.60 (95\% CI 1.56-8.30)] were obese compared with control subjects. Waist circumference and waist-to-height ratio, surrogates for central adiposity and sensitive indicators of metabolic risk, were also seen more frequently increased in psoriatic children [10].

The relationship between obesity and pediatric psoriasis deserves further investigation. Pediatric psoriasis has been associated with decreased quality of life as well as decreased tendency to participate in physical activities because of increased pruritus with sweating and increased visibility of the psoriatic lesions to peers [7, 9, 12, 121]. These factors theoretically could contribute to pediatric obesity, but only after the occurrence of psoriasis. On the other hand, psoriasis could instead be a complication of obesity, with systemic inflammation associated with obesity predisposing to the occurrence of psoriasis $[10,122]$. Becker et al. demonstrated in a pilot study that being overweight or obese preceded psoriasis by at least 2 years in $93 \%$ of children with psoriasis [11]. In these children, percentages of immediate family members with obesity and psoriasis were 48 and $41 \%$, respectively. Although it is unclear whether weight loss reduces psoriasis severity in children, just as it remains controversial in adults, lifestyle education and weight-loss programs in these families should be recommended [11, 123].

In addition to obesity, the presence of the metabolic syndrome is an issue in pediatric psoriasis patients. The metabolic syndrome in children is defined as having at least three of the following: (1) fasting triglycerides $\geq 1.1 \mathrm{mmol} /$ $\mathrm{L}$; (2) high-density lipoprotein $<1.3 \mathrm{mmol} / \mathrm{L}$, except in boys aged 15-19 years, in whom the cut-off point is $<1.2 \mathrm{mmol} / \mathrm{L}$; (3) fasting glucose $\geq 6.1 \mathrm{mmol} / \mathrm{L}$; (4) waist circumference $>75$ th percentile for age and gender; and (5) systolic blood pressure $>90$ th percentile for gender, age and height (Fig. 1) [124]. In a small study in 20 children, the prevalence of metabolic syndrome was significantly higher in pediatric psoriasis patients (30\%) compared with the age- and gender-matched control subjects (7.4\%). No differences in BMI or individual components of metabolic syndrome were found [125]. Childhood onset of psoriasis does not seem to be an additional risk factor for the higher prevalence of metabolic comorbidities and cardiovascular disease in adulthood [126].

Pediatric psoriasis could have detrimental effects on quality of life. Because of substantial developmental changes in early life, children are a vulnerable group. Psoriasis can disrupt their social relationships and interfere with school and sport [7]. The Children Dermatology Life Quality Index (CDLQI) was developed to allow quality-oflife assessment in children with psoriasis and other skin disorders [127]. Oostveen et al. conducted a prospective observational study of children with psoriasis from a registry containing daily clinical practice data [9]. They assessed the CDLQI in a cohort of 125 patients, finding that psoriasis has a negative impact on quality of life. The questions related to itching and their treatment regimens seemed to have the highest impact on the quality of life of these children. Effective interventions had a positive effect on quality of life, primarily through improving complaints of itch and sleep disturbance $[9,128]$.
Fig. 1 Pediatric definition of the metabolic syndrome. Figure adapted from de Ferranti et al. [124]

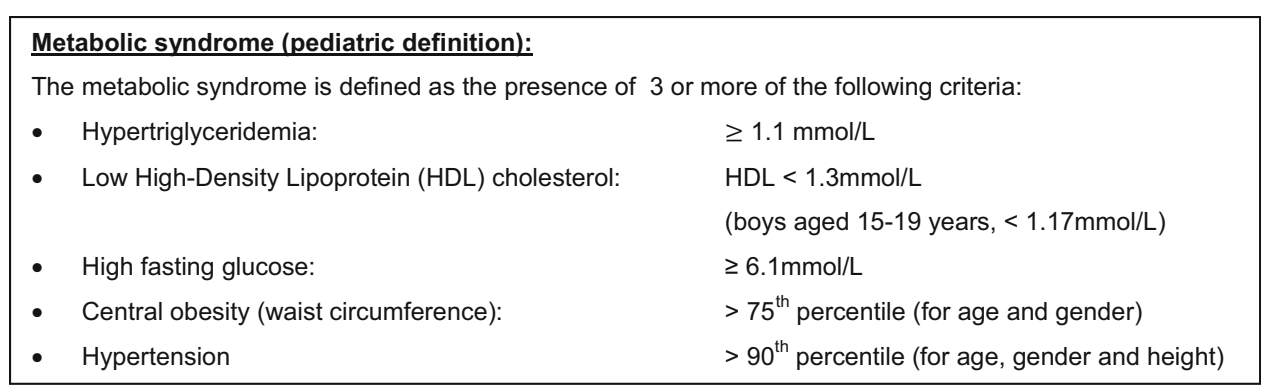


Previous research in adult populations reported psychiatric symptoms and diagnoses, such as depression and anxiety, in up to $60 \%$ of psoriasis patients. Although studies regarding psychiatric symptoms in pediatric psoriasis are limited, it is known that pain, itching and the visible psoriasis lesions can result in embarrassment, social discomfort and anxiety in pediatric psoriasis patients [129, 130]. In line with these findings, Kimball et al. demonstrated an increased risk of developing depression, anxiety and bipolar disorder in psoriatic children compared with control subjects [12]. In addition, children suffering from psoriasis had a $47 \%$ greater risk of taking psychotropic medications. Since the rate of antidepressant and anxiolytic medication use is higher than the incidences of depression and anxiety disorder in this study, and psychotropic medications are more likely to be used for more severe cases, the true incidence of psychiatric diagnoses may be even higher [12]. The relationship between psoriasis and depression and impaired quality of life in children has also been reported by other research groups $[8,131]$.

\section{Conclusion}

Psoriasis begins in childhood in almost one-third of the cases and is increasing in prevalence and incidence. However, the evidence on treatment efficacy and safety is still limited, and long-term data in pediatric patients are lacking. A prospective, multicenter, international registry is needed to evaluate these treatments in a standardized manner and ultimately to develop international guidelines on pediatric psoriasis.

Conflict of interest IMGJ Bronckers declares no conflict of interest. AS Paller was an investigator without honorarium for AbbVie, Amgen and Stiefel/GSK, and was a consultant and received honorarium from AbbVie and Celgene. MMB Seyger received grants from/was involved in clinical trials from AbbVie, Almirall, Astellas, Leo Pharma, and Pfizer, and has served as a consultant for AbbVie, Almirall, Boehringer Ingelheim, Celgene and Pfizer. PCM van de Kerkhof has carried out clinical trials for Centocor, Pfizer, Schering Plough, AbbVie, Philips Lighting, Novartis, GSK, Eli Lilly, Amgen and Almirall, and has consultancy services for Schering Plough, Celgene, Centocor, Almirall, Pfizer, AbbVie, Actelion, Galderma, Novartis, and Janssen. MJ van Geel has carried out clinical trials for AbbVie, Astellas, Leo Pharma, and Pfizer, and has received speaking fees from MSD and reimbursement for attending a symposium from Pfizer and Janssen.

Funding/support No funding has been received for the preparation of this manuscript.

Open Access This article is distributed under the terms of the Creative Commons Attribution-NonCommercial 4.0 International License (http://creativecommons.org/licenses/by-nc/4.0/), which permits any noncommercial use, distribution, and reproduction in any medium, provided you give appropriate credit to the original author(s) and the source, provide a link to the Creative Commons license, and indicate if changes were made.

\section{References}

1. Augustin M, Glaeske G, Radtke MA, Christophers E, Reich K, Schafer I. Epidemiology and comorbidity of psoriasis in children. Br J Dermat. 2010;162(3):633-6.

2. Christophers E. Psoriasis-epidemiology and clinical spectrum. Clin Exp Dermatol. 2001;26(4):314-20.

3. Parisi R, Symmons DP, Griffiths CE, Ashcroft DM. Identification, Management of Psoriasis and Associated Comorbidity Project. Global epidemiology of psoriasis: a systematic review of incidence and prevalence. $J$ Invest Dermatol. 2013;133(2):377-85.

4. Gelfand JM, Weinstein R, Porter SB, Neimann AL, Berlin JA, Margolis DJ. Prevalence and treatment of psoriasis in the United Kingdom: a population-based study. Arch Dermatol. 2005;141(12):1537-41.

5. Raychaudhuri SP, Gross J. A comparative study of pediatric onset psoriasis with adult onset psoriasis. Pediatr Dermatol. 2000;17(3):174-8.

6. Tollefson MM, Crowson CS, McEvoy MT, Maradit Kremers H. Incidence of psoriasis in children: a population-based study. J Am Acad Dermatol. 2010;62(6):979-87.

7. de Jager ME, De Jong EM, Evers AW, Van De Kerkhof PC, Seyger MM. The burden of childhood psoriasis. Pediatr Dermatol. 2011;28(6):736-7.

8. Bilgic A, Bilgic O, Akis HK, Eskioglu F, Kilic EZ. Psychiatric symptoms and health-related quality of life in children and adolescents with psoriasis. Pediatr Dermatol. 2010;27(6):614-7.

9. Oostveen AM, de Jager ME, van de Kerkhof PC, Donders AR, de Jong EM, Seyger MM. The influence of treatments in daily clinical practice on the Children's Dermatology Life Quality Index in juvenile psoriasis: a longitudinal study from the ChildCAPTURE patient registry. Br J Dermatol. 2012;167(1):145-9.

10. Paller AS, Mercy K, Kwasny MJ, Choon SE, Cordoro KM, Girolomoni G, et al. Association of pediatric psoriasis severity with excess and central adiposity: an international cross-sectional study. JAMA Dermatol. 2013;149(2):166-76.

11. Becker L, Tom WL, Eshagh K, Benjamin LT, Paller AS. Excess adiposity preceding pediatric psoriasis. JAMA Dermatol. 2014;150(5):573-4.

12. Kimball AB, Wu EQ, Guerin A, Yu AP, Tsaneva M, Gupta SR, et al. Risks of developing psychiatric disorders in pediatric patients with psoriasis. J Am Acad Dermatol. 2012;67(4):651-7 (e1-2).

13. De Jager ME, Van de Kerkhof PC, De Jong EM, Seyger MM. Epidemiology and prescribed treatments in childhood psoriasis: a survey among medical professionals. J Dermatol Treat. 2009;20(5):254-8.

14. Matusiewicz D, Koerber A, Schadendorf D, Wasem J, Neumann A. Childhood psoriasis - an analysis of German health insurance data. Pediatr Dermatol. 2014;31(1):8-13.

15. Yang YC, Cheng YW, Lai CS, Chen W. Prevalence of childhood acne, ephelides, warts, atopic dermatitis, psoriasis, alopecia areata and keloid in Kaohsiung County, Taiwan: a community-based clinical survey. J Eur Acad Dermatol Venereol: JEADV. 2007;21(5):643-9.

16. Chen GY, Cheng YW, Wang CY, Hsu TJ, Hsu MM, Yang PT, et al. Prevalence of skin diseases among schoolchildren in Magong, Penghu, Taiwan: a community-based clinical survey. Journal of the Formosan Medical Association =. Taiwan yi zhi. 2008;107(1):21-9.

17. Griffiths CE, Barker JN. Pathogenesis and clinical features of psoriasis. Lancet. 2007;370(9583):263-71.

18. Tsankov N, Angelova I, Kazandjieva J. Drug-induced psoriasis. Recognition and management. Am J Clin Dermatol. 2000;1(3):159-65. 
19. Cullen G, Kroshinsky D, Cheifetz AS, Korzenik JR. Psoriasis associated with anti-tumour necrosis factor therapy in inflammatory bowel disease: a new series and a review of 120 cases from the literature. Aliment Pharmacol Ther. 2011;34(11-12):1318-27.

20. Perman MJ, Lovell DJ, Denson LA, Farrell MK, Lucky AW. Five cases of anti-tumor necrosis factor alpha-induced psoriasis presenting with severe scalp involvement in children. Pediatr Dermatol. 2012;29(4):454-9.

21. Fan X, Xiao FL, Yang S, Liu JB, Yan KL, Liang YH, et al. Childhood psoriasis: a study of 277 patients from China. J Eur Acad Dermatol Venereol: JEADV. 2007;21(6):762-5.

22. Kumar B, Jain R, Sandhu K, Kaur I, Handa S. Epidemiology of childhood psoriasis: a study of 419 patients from northern India. Int J Dermatol. 2004;43(9):654-8.

23. Morris A, Rogers M, Fischer G, Williams K. Childhood psoriasis: a clinical review of 1262 cases. Pediatr Dermatol. 2001;18(3):188-98.

24. Nanda A, Kaur S, Kaur I, Kumar B. Childhood psoriasis: an epidemiologic survey of 112 patients. Pediatr Dermatol. 1990;7(1):19-21.

25. Mercy K, Kwasny M, Cordoro KM, Menter A, Tom WL, Korman N, et al. Clinical manifestations of pediatric psoriasis: results of a multicenter study in the United States. Pediatr Dermatol. 2013;30(4):424-8.

26. Chiam LY, de Jager ME, Giam YC, de Jong EM, van de Kerkhof PC, Seyger MM. Juvenile psoriasis in European and Asian children: similarities and differences. $\mathrm{Br} \mathrm{J}$ Dermatol. 2011;164(5):1101-3.

27. al-Fouzan AS, Nanda A. A survey of childhood psoriasis in Kuwait. Pediatr Dermatol. 1994;11(2):116-9.

28. Seyhan M, Coskun BK, Saglam H, Ozcan H, Karincaoglu Y. Psoriasis in childhood and adolescence: evaluation of demographic and clinical features. Pediatr Int. 2006;48(6):525-30.

29. Shah KN. Diagnosis and treatment of pediatric psoriasis: current and future. Am J Clin Dermatol. 2013;14(3):195-213.

30. Kwon HH, Na SJ, Jo SJ, Youn JI. Epidemiology and clinical features of pediatric psoriasis in tertiary referral psoriasis clinic. J Dermatol. 2012;39(3):260-4.

31. Dogra S, Kaur I. Childhood psoriasis. Indian J Dermatol Venereol Leprol. 2010;76(4):357-65.

32. Tollefson MM. Diagnosis and management of psoriasis in children. Pediatr Clin North Am. 2014;61(2):261-77.

33. Benoit S, Hamm H. Childhood psoriasis. Clin Dermatol. 2007;25(6):555-62.

34. Silverberg NB. Pediatric psoriasis: an update. Ther Clin Risk Manag. 2009;5:849-56.

35. Howard R, Tsuchiya A. Adult skin disease in the pediatric patient. Dermatol Clin. 1998;16(3):593-608.

36. Busch AL, Landau JM, Moody MN, Goldberg LH. Pediatric psoriasis. Skin Therapy Lett. 2012;17(1):5-7.

37. Martin BA, Chalmers RJ, Telfer NR. How great is the risk of further psoriasis following a single episode of acute guttate psoriasis? Arch Dermatol. 1996;132(6):717-8.

38. Setta-Kaffetzi N, Navarini AA, Patel VM, Pullabhatla V, Pink $\mathrm{AE}$, Choon SE, et al. Rare pathogenic variants in IL36RN underlie a spectrum of psoriasis-associated pustular phenotypes. J Invest Dermatol. 2013;133(5):1366-9.

39. Liao PB, Rubinson R, Howard R, Sanchez G, Frieden IJ. Annular pustular psoriasis-most common form of pustular psoriasis in children: report of three cases and review of the literature. Pediatr Dermatol. 2002;19(1):19-25.

40. Brazzelli V, Carugno A, Alborghetti A, Grasso V, Cananzi R, Fornara L, et al. Prevalence, severity and clinical features of psoriasis in fingernails and toenails in adult patients: Italian experience. J Eur Acad Dermatol Venereol: JEADV. 2012;26(11):1354-9.

41. Schachner LA, Hansen RC. Pediatric dermatology. 4th ed. Philadelphia: Elsevier Ltd; 2011.

42. Stoll ML, Zurakowski D, Nigrovic LE, Nichols DP, Sundel RP, Nigrovic PA. Patients with juvenile psoriatic arthritis comprise two distinct populations. Arthritis Rheum. 2006;54(11):3564-72.

43. Flato B, Lien G, Smerdel-Ramoya A, Vinje O. Juvenile psoriatic arthritis: longterm outcome and differentiation from other subtypes of juvenile idiopathic arthritis. J Rheumatol. 2009;36(3):642-50.

44. Krumrey-Langkammerer M, Hafner R. Evaluation of the ILAR criteria for juvenile idiopathic arthritis. J Rheumatol. 2001;28(11):2544-7.

45. Saurenmann RK, Levin AV, Feldman BM, Rose JB, Laxer RM, Schneider R, et al. Prevalence, risk factors, and outcome of uveitis in juvenile idiopathic arthritis: a long-term followup study. Arthritis Rheum. 2007;56(2):647-57.

46. Danner S, Sordet C, Terzic J, Donato L, Velten M, Fischbach M, et al. Epidemiology of juvenile idiopathic arthritis in Alsace, France. J Rheumatol. 2006;33(7):1377-81.

47. Butbul Aviel Y, Tyrrell P, Schneider R, Dhillon S, Feldman BM, Laxer R, et al. Juvenile psoriatic arthritis (JPsA): juvenile arthritis with psoriasis? Pediatr Rheumatol Online J. 2013;11(1):11.

48. Sticherling M, Minden K, Kuster RM, Krause A, Borte M. Psoriasis and psoriasis arthritis in childhood and adolescence. Overview and consensus statement of the 9th Worlitz Expert Round Table Discussion 2006 for the Society for Child and Adolescent Rheumatology. Z Rheumatol. 2007;66(4):349-54.

49. Zachariae H. Prevalence of joint disease in patients with psoriasis: implications for therapy. Am J Clin Dermatol. 2003;4(7):441-7.

50. Wittkowski KM, Leonardi C, Gottlieb A, Menter A, Krueger GG, Tebbey PW, et al. Clinical symptoms of skin, nails, and joints manifest independently in patients with concomitant psoriasis and psoriatic arthritis. PLoS One. 2011;6(6):e20279.

51. Nestle FO, Kaplan DH, Barker J. Psoriasis. N Engl J Med. 2009;361(5):496-509.

52. Murphy M, Kerr P, Grant-Kels JM. The histopathologic spectrum of psoriasis. Clin Dermatol. 2007;25(6):524-8.

53. Stahle M, Atakan N, Boehncke WH, Chimenti S, Dauden E, Giannetti A, et al. Juvenile psoriasis and its clinical management: a European expert group consensus. J Ger Soc Dermatol. 2010;8(10):812-8.

54. Moscarella E, Longo C, Zalaudek I, Argenziano G, Piana S, Lallas A. Dermoscopy and confocal microscopy clues in the diagnosis of psoriasis and porokeratosis. J Am Acad Dermatol. 2013;69(5):e231-3.

55. Lallas A, Kyrgidis A, Tzellos TG, Apalla Z, Karakyriou E, Karatolias A, et al. Accuracy of dermoscopic criteria for the diagnosis of psoriasis, dermatitis, lichen planus and pityriasis rosea. Br J Dermatol. 2012;166(6):1198-205.

56. Luersen K, Davis SA, Kaplan SG, Abel TD, Winchester WW, Feldman SR. Sticker charts: a method for improving adherence to treatment of chronic diseases in children. Pediatr Dermatol. 2012;29(4):403-8.

57. Tan X, Feldman SR, Chang J, Balkrishnan R. Topical drug delivery systems in dermatology: a review of patient adherence issues. Expert Opin Drug Deliv. 2012;9(10):1263-71.

58. Davis SA, Lin HC, $\mathrm{Yu} \mathrm{CH}$, Balkrishnan R, Feldman SR. Underuse of early follow-up visits: a missed opportunity to improve patients' adherence. J Drugs Dermatol: JDD. 2014;13(7):833-6. 
59. Lara-Corrales I, Xi N, Pope E. Childhood psoriasis treatment: evidence published over the last 5 years. Rev Recent Clin Trials. 2011;6(1):36-43.

60. Fotiadou C, Lazaridou E, Ioannides D. Management of psoriasis in adolescence. Adolesc Health Med Ther. 2014;5:25-34.

61. Sticherling M, Augustin M, Boehncke WH, Christophers E, Domm S, Gollnick H, et al. Therapy of psoriasis in childhood and adolescence-a German expert consensus. J Ger Soc Dermatol. 2011;9(10):815-23.

62. Bhutani T, Kamangar F, Cordoro KM. Management of pediatric psoriasis. Pediatr Ann. 2012;41(1):e1-7.

63. de Jager ME, de Jong EM, van de Kerkhof PC, Seyger MM. Efficacy and safety of treatments for childhood psoriasis: a systematic literature review. J Am Acad Dermatol. 2010;62(6):1013-30.

64. Kimball AB, Gold MH, Zib B, Davis MW, Clobetasol Propionate Emulsion Formulation Foam Phase IIICSG. Clobetasol propionate emulsion formulation foam $0.05 \%$ : review of phase II open-label and phase III randomized controlled trials in steroid-responsive dermatoses in adults and adolescents. J Am Acad Dermatol. 2008;59(3):448-54 (54 e1).

65. Herz G, Blum G, Yawalkar S. Halobetasol propionate cream by day and halobetasol propionate ointment at night for the treatment of pediatric patients with chronic, localized plaque psoriasis and atopic dermatitis. J Am Acad Dermatol. 1991;25(6 Pt 2):1166-9.

66. Darley CR, Cunliffe WJ, Green CM, Hutchinson PE, Klaber MR, Downes N. Safety and efficacy of calcipotriol ointment (Dovonex) in treating children with psoriasis vulgaris. $\mathrm{Br} \mathrm{J}$ Dermatol. 1996;135(3):390-3.

67. Oranje AP, Marcoux D, Svensson A, Prendiville J, Krafchik B, Toole J, et al. Topical calcipotriol in childhood psoriasis. J Am Acad Dermatol. 1997;36(2 Pt 1):203-8.

68. van de Kerkhof PC, Hoffmann V, Anstey A, Barnes L, Bolduc $\mathrm{C}$, Reich K, et al. A new scalp formulation of calcipotriol plus betamethasone dipropionate compared with each of its active ingredients in the same vehicle for the treatment of scalp psoriasis: a randomized, double-blind, controlled trial. Br J Dermatol. 2009;160(1):170-6.

69. van Geel MJ, Mul K, Oostveen AM, van de Kerkhof PC, de Jong EM, Seyger MM. Calcipotriol/betamethasone dipropionate ointment in mild-to-moderate paediatric psoriasis: long-term daily clinical practice data in a prospective cohort. Br J Dermatol. 2014;171(2):363-9.

70. Gooderham M, Debarre JM, Keddy-Grant J, Xu Z, Kurvits M, Goodfield M. Safety and efficacy of calcipotriol plus betamethasone dipropionate gel in the treatment of scalp psoriasis in adolescents $12-17$ years of age. $\mathrm{Br} \mathrm{J}$ Dermatol. 2014;171(6):1470-7.

71. Oostveen AM, de Jong EM, Donders AR, van de Kerkhof PC, Seyger MM. Treatment of paediatric scalp psoriasis with calcipotriene/betamethasone dipropionate scalp formulation: effectiveness, safety and influence on children's quality of life in daily practice. J Eur Acad Dermatol Venereol: JEADV. 2015;29(6):1193-7.

72. Wang C, Lin A. Efficacy of topical calcineurin inhibitors in psoriasis. J Cutan Med Surg. 2014;18(1):8-14.

73. Steele JA, Choi C, Kwong PC. Topical tacrolimus in the treatment of inverse psoriasis in children. J Am Acad Dermatol. 2005;53(4):713-6.

74. Brune A, Miller DW, Lin P, Cotrim-Russi D, Paller AS. Tacrolimus ointment is effective for psoriasis on the face and intertriginous areas in pediatric patients. Pediatr Dermatol. 2007;24(1):76-80.

75. de Jager ME, van de Kerkhof PC, de Jong EM, Seyger MM. Dithranol therapy in childhood psoriasis: unjustifiably on the verge of falling into oblivion. Dermatology. 2010;220(4):329-32.

76. Oostveen AM, Beulens CA, van de Kerkhof PC, de Jong EM, Seyger MM. The effectiveness and safety of short-contact dithranol therapy in paediatric psoriasis: a prospective comparison of regular day care and day care with telemedicine. $\mathrm{Br} \mathrm{J}$ Dermatol. 2014;170(2):454-7.

77. Zamberk P, Velazquez D, Campos M, Hernanz JM, Lazaro P. Paediatric psoriasis-narrowband UVB treatment. J Eur Acad Dermatol Venereol: JEADV. 2010;24(4):415-9.

78. Pavlovsky M, Baum S, Shpiro D, Pavlovsky L, Pavlotsky F. Narrow band UVB: is it effective and safe for paediatric psoriasis and atopic dermatitis? J Eur Acad Dermatol Venereol: JEADV. 2011;25(6):727-9.

79. Lara-Corrales I, Ramnarine S, Lansang P. Treatment of childhood psoriasis with phototherapy and photochemotherapy. Clin Med Insights Pediatr. 2013;7:25-33.

80. Jury CS, McHenry P, Burden AD, Lever R, Bilsland D. Narrowband ultraviolet $B$ (UVB) phototherapy in children. Clin Exp Dermatol. 2006;31(2):196-9.

81. Patel RV, Clark LN, Lebwohl M, Weinberg JM. Treatments for psoriasis and the risk of malignancy. J Am Acad Dermatol. 2009;60(6):1001-17.

82. Archier E, Devaux S, Castela E, Gallini A, Aubin F, Le Maitre $\mathrm{M}$, et al. Carcinogenic risks of psoralen UV-A therapy and narrowband UV-B therapy in chronic plaque psoriasis: a systematic literature review. J Eur Acad Dermatol Venereol: JEADV. 2012;26(Suppl 3):22-31.

83. Chen X, Yang M, Cheng Y, Liu GJ, Zhang M. Narrow-band ultraviolet B phototherapy versus broad-band ultraviolet B or psoralen-ultraviolet A photochemotherapy for psoriasis. Cochrane Database Syst Rev. 2013;10:CD009481.

84. Zweegers J, de Jong EM, Nijsten TE, de Bes J, te Booij M, Bogonjen RJ, et al. Summary of the Dutch S3-guidelines on the treatment of psoriasis 2011. Dermatol Online J. 2014;20(3):1-112.

85. van Geel MJ, Mul K, de Jager ME, van de Kerkhof PC, de Jong EM, Seyger MM. Systemic treatments in paediatric psoriasis: a systematic evidence-based update. J Eur Acad Dermatol Venereol: JEADV. 2015;29(3):425-37.

86. Wright NA, Piggott CD, Eichenfield LF. The role of biologics and other systemic agents in the treatment of pediatric psoriasis. Semin Cutan Med Surg. 2010;29(1):20-7.

87. Geel MJ, Oostveen AM, Hoppenreijs EP, Hendriks JC, Kerkhof $\mathrm{PC}$, de Jong EM, et al. Methotrexate in pediatric plaque-type psoriasis: long-term daily clinical practice results from the Child-CAPTURE registry. J Dermatol Treat. 2015;20:1-7.

88. Posso-De Los Rios CJ, Pope E, Lara-Corrales I. A systematic review of systemic medications for pustular psoriasis in pediatrics. Pediatr Dermatol. 2014;31(4):430-9.

89. Marqueling AL, Cordoro KM. Systemic treatments for severe pediatric psoriasis: a practical approach. Dermatol Clin. 2013;31(2):267-88.

90. Pathirana D, Ormerod AD, Saiag P, Smith C, Spuls PI, Nast A, et al. European S3-guidelines on the systemic treatment of psoriasis vulgaris. J Eur Acad Dermatol Venereol: JEADV. 2009;23(Suppl 2):1-70.

91. Kaur I, Dogra S, De D, Kanwar AJ. Systemic methotrexate treatment in childhood psoriasis: further experience in 24 children from India. Pediatr Dermatol. 2008;25(2):184-8.

92. Hashkes PJ, Becker ML, Cabral DA, Laxer RM, Paller AS, Rabinovich CE, et al. Methotrexate: new uses for an old drug. J Pediatr. 2014;164(2):231-6.

93. Kilic SS, Hacimustafaoglu M, Celebi S, Karadeniz A, Ildirim I. Low dose cyclosporin A treatment in generalized pustular psoriasis. Pediatr Dermatol. 2001;18(3):246-8. 
94. Mahe E, Bodemer C, Pruszkowski A, Teillac-Hamel D, de Prost Y. Cyclosporine in childhood psoriasis. Arch Dermatol. 2001;137(11):1532-3.

95. Alli N, Gungor E, Karakayali G, Lenk N, Artuz F. The use of cyclosporin in a child with generalized pustular psoriasis. $\mathrm{Br} \mathbf{J}$ Dermatol. 1998;139(4):754-5.

96. Kim HS, Kim GM, Kim SY. Two-stage therapy for childhood generalized pustular psoriasis: low-dose cyclosporin for induction and maintenance with acitretin/narrowband ultraviolet $\mathrm{B}$ phototherapy. Pediatr Dermatol. 2006;23(3):306-8.

97. Chao PH, Cheng YW, Chung MY. Generalized pustular psoriasis in a 6-week-old infant. Pediatr Dermatol. 2009;26(3):352-4.

98. Sarkar S, Das K, Roychoudhury S, Shrimal A. Pseudotumor cerebri in a child treated with acitretin: a rare occurrence. Indian J Pharmacol. 2013;45(1):89-90.

99. Cordoro KM. Management of childhood psoriasis. Adv Dermatol. 2008;24:125-69.

100. Balak DM, Oostveen AM, Bousema MT, Venema AW, Arnold WP, Seyger MM, et al. Effectiveness and safety of fumaric acid esters in children with psoriasis: a retrospective analysis of 14 patients from The Netherlands. $\mathrm{Br} \mathrm{J}$ Dermatol. 2013;168(6):1343-7.

101. Hoefnagel JJ, Thio HB, Willemze R. Bouwes Bavinck JN. Long-term safety aspects of systemic therapy with fumaric acid esters in severe psoriasis. Br J Dermatol. 2003;149(2):363-9.

102. Gerdes S, Domm S, Mrowietz U. Long-term treatment with fumaric acid esters in an 11-year-old male child with psoriasis. Dermatology. 2011;222(3):198-200.

103. Steeman AS, Balak DM, Seijger MMB, Thio HB, Bousema MT. Fumaraten bij een meisje van vijftien jaar met psoriasis! Nederlands Tijdschrift voor Dermatologie \& Venereologie. 2012;22(5):308-11

104. Gunther $\mathrm{CH}$. Successive use of fumaric acid esters for the treatment of psoriasis vulgaris in a 14-year-old patient [German]. Der Hautarzt; Zeitschrift fur Dermatologie, Venerologie, und verwandte Gebiete. 2004;15(1):28-30.

105. Paller AS, Siegfried EC, Langley RG, Gottlieb AB, Pariser D, Landells I, et al. Etanercept treatment for children and adolescents with plaque psoriasis. N Engl J Med. 2008;358(3):241-51.

106. Luu M, Cordoro KM. The evolving role of biologics in the treatment of pediatric psoriasis. Skin Therapy Lett. 2013;18(2):1-4.

107. Sukhatme SV, Gottlieb AB. Pediatric psoriasis: updates in biologic therapies. Dermatol Therapy. 2009;22(1):34-9.

108. Paller AS, Siegfried EC, Eichenfield LF, Pariser D, Langley RG, Creamer K, et al. Long-term etanercept in pediatric patients with plaque psoriasis. J Am Acad Dermatol. 2010;63(5):762-8.

109. Lovell DJ, Reiff A, Ilowite NT, Wallace CA, Chon Y, Lin SL, et al. Safety and efficacy of up to eight years of continuous etanercept therapy in patients with juvenile rheumatoid arthritis. Arthritis Rheum. 2008;58(5):1496-504.

110. Prince FH, Twilt M, ten Cate R, van Rossum MA, Armbrust W, Hoppenreijs EP, et al. Long-term follow-up on effectiveness and safety of etanercept in juvenile idiopathic arthritis: the Dutch national register. Ann Rheum Dis. 2009;68(5):635-41.

111. Bellodi Schmidt F, Shah KN. Biologic response modifiers and pediatric psoriasis. Pediatr Dermatol. 2015;32(3):303-20.

112. Dini V, Barbanera S, Romanelli M. Efficacy of adalimumab for the treatment of refractory paediatric acrodermatitis continua of hallopeau. Acta Dermato-Venereologica. 2013;93(5):588-9.

113. Moretti D, Cianchi I, Vannucci G, Cimaz R, Simonini G. Psoriatic juvenile idiopathic arthritis associated with uveitis: a case report. Case Rep Rheumatol. 2013;2013:595890.

114. A double blind study in pediatric subjects with chronic plaque psoriasis, studying adalimumab vs methotrexate [online]. https://
www.clinicaltrials.gov/ct2/show/NCT01251614. NLM identifier: NCT01251614. Accessed 4 May 2015.

115. Fotiadou C, Lazaridou E, Giannopoulou C, Ioannides D. Ustekinumab for the treatment of an adolescent patient with recalcitrant plaque psoriasis. Eur $J$ Dermatol: EJD. 2011;21(1):117-8.

116. Dixit S, Shumack S, Fischer G. Ustekinumab in the treatment of severe paediatric psoriasis. Aust J Dermatol. 2013;54(2):147.

117. AbuHilal M, Ho N. Successful treatment of severe psoriasis in an adolescent with ustekinumab. Pediatr Dermatol. 2015;32(3):377-80.

118. A study of the safety and efficacy of ustekinumab in adolescent patients with psoriasis (CADMUS) [online]. https:// clinicaltrials.gov/ct2/show/NCT01090427. NLM identifier: NCT01090427. Accessed 28 December 2014.

119. Augustin M, Reich K, Glaeske G, Schaefer I, Radtke M. Comorbidity and age-related prevalence of psoriasis: analysis of health insurance data in Germany. Acta Dermato-Venereologica. 2010;90(2):147-51.

120. Koebnick C, Black MH, Smith N, Der-Sarkissian JK, Porter AH, Jacobsen SJ, et al. The association of psoriasis and elevated blood lipids in overweight and obese children. J Pediatr. 2011;159(4):577-83.

121. de Jager ME, van de Kerkhof PC, de Jong EM, Seyger MM. A cross-sectional study using the Children's Dermatology Life Quality Index (CDLQI) in childhood psoriasis: negative effect on quality of life and moderate correlation of CDLQI with severity scores. Br J Dermatol. 2010;163(5):1099-101.

122. Mercy KM, Paller AS. The relationship between obesity and psoriasis in the pediatric population: implications and future directions. Cutis. 2013;92(3):107-9.

123. Jensen P, Zachariae C, Christensen R, Geiker NR, Schaadt BK, Stender S, et al. Effect of weight loss on the severity of psoriasis: a randomized clinical study. JAMA Dermatol. 2013;149(7):795-801.

124. de Ferranti SD, Gauvreau K, Ludwig DS, Neufeld EJ, Newburger JW, Rifai N. Prevalence of the metabolic syndrome in American adolescents: findings from the Third National Health and Nutrition Examination Survey. Circulation. 2004;110(16):2494-7.

125. Au SC, Goldminz AM, Loo DS, Dumont N, Levine D, Volf E, et al. Association between pediatric psoriasis and the metabolic syndrome. J Am Acad Dermatol. 2012;66(6):1012-3.

126. Mahe E, Maccari F, Beauchet A, Lahfa M, Barthelemy H, Reguiai Z, et al. Childhood-onset psoriasis: association with future cardiovascular and metabolic comorbidities. Br J Dermatol. 2013;169(4):889-95.

127. Lewis-Jones MS, Finlay AY. The Children's Dermatology Life Quality Index (CDLQI): initial validation and practical use. Br J Dermatol. 1995;132(6):942-9.

128. Langley RG, Paller AS, Hebert AA, Creamer K, Weng HH, Jahreis A, et al. Patient-reported outcomes in pediatric patients with psoriasis undergoing etanercept treatment: 12-week results from a phase III randomized controlled trial. J Am Acad Dermatol. 2011;64(1):64-70.

129. Akay A, Pekcanlar A, Bozdag KE, Altintas L, Karaman A. Assessment of depression in subjects with psoriasis vulgaris and lichen planus. J Eur Acad Dermatol Venereol: JEADV. 2002;16(4):347-52.

130. Russo PA, Ilchef R, Cooper AJ. Psychiatric morbidity in psoriasis: a review. Aust J Dermatol. 2004;45(3):155-9 (quiz 60-1).

131. Remrod C, Sjostrom K, Svensson A. Psychological differences between early- and late-onset psoriasis: a study of personality traits, anxiety and depression in psoriasis. $\mathrm{Br} \mathrm{J}$ Dermatol. 2013;169(2):344-50. 